\title{
A utilização das informações de custos na gestão da saúde pública: um estudo preliminar em secretarias municipais de saúde do estado de Santa Catarina*
}

\author{
André Graf de Almeida** \\ José Alonso Borba*** \\ Luiz Carlos da Silva Flores****
}

Sumário: 1. Introdução; 2. Revisão da literatura; 3. Metodologia; 4. Apresentação e análise dos resultados; 5 . Conclusões.

Summary: 1. Introduction; 2. Literature review; 3. Methodology; 4. Results and analysis; 5. Conclusion.

Palavras-chave: contabilidade de custos; Sistema Único de Saúde; administração pública.

KEY WORDS: cost accounting; Unified Health System; public management.

Este artigo analisa o uso das informações de custos pelos gestores de 20 grandes secretarias municipais da saúde do estado de Santa Catarina. Para isso, foi avaliado o perfil dos gestores entrevistados; foi verificada a existência ou não de sistemas de custos implantados nessas secretarias; foi feita uma avaliação da percepção desses gestores sobre a utilização das informações de custos no processo de tomada de decisão e foram identificadas quais informações de custos são utilizadas atualmente na

\footnotetext{
* Artigo recebido em jun. 2008 e aceito em mar. 2009.

** Mestre em administração. Professor da Universidade do Vale do Itajaí (Univali). Endereço: Rua Arapongas, 455 - Bairro Ariribá - CEP 88338-630, Balneário Camboriú, SC, Brasil. E-mail: andrealmeida@univali.br.

$* * *$ Doutor em contabilidade. Professor da Universidade Federal de Santa Catarina (UFSC). Endereço: Rua Arlindo Penna, 42 - CEP 88037-260, Florianópolis, SC, Brasil. E-mail: jalonso1@ terra.com.br.

***** Doutor em engenharia de produção. Professor da Universidade do Vale do Itajaí (Univali). Endereço: Rua Estudante Renato Victorino, 80 — CEP 88307-250, Itajaí, SC, Brasil. E-mail: luiz. flores@univali.br.
} 
gestão desses órgãos. Os entrevistados foram os ocupantes de cargos administrativos nas secretarias municipais da saúde pesquisadas. Conseguiu-se avaliar o uso das informações de custos na gestão de 18 secretarias municipais da saúde do estado de Santa Catarina. Os resultados indicam que apenas duas secretarias municipais da saúde possuem esse processo um pouco mais avançado; nas demais, o que se verifica é que existem algumas tentativas de se obter informações mais detalhadas sobre custos. Entretanto, na opinião dos entrevistados, as informações de custos são bastante importantes na gestão das secretarias.

The use of costs information in public health: a preliminary study in local health departments in the state of Santa Catarina

This article analyzes the use of costs information in decision-making by managers of the 20 local health departments in the state of Santa Catarina, Brazil. Public managers profiles were assessed so as to verify whether they had the schooling and experience needed to produce ethical information on certain issues. The existence of costs systems in such departments was assessed through the managers' perceptions of the use of costs information in the decision-making process, and which information is actually used. The methodology used was guided interviews, and the subjects were public employees withholding managing positions in local health departments. The goals of the study were reached as 18 local health departments in the state of Santa Catarina were assessed on their use of costs information. Results show that in spite of existing a legal requirement concerning the implementation of costs systems in public departments, only two local health departments actually have this advanced tool. In the remaining ones there are attempts to obtain more detailed costs data. However, according to the interviewees, costs information is definitely crucial when managing any department.

\section{Introdução}

A gestão de custos em qualquer tipo de organização é útil e proporciona ao administrador uma visão mais acurada e ampliada da realidade financeira, já que permite olhar por outro ângulo como são gastos os recursos disponíveis, permitindo identificar os exageros e destinar os recursos na quantidade certa para serem aplicados nas atividades mais necessárias. A gestão de custos visa não somente gastar menos, mas principalmente gastar melhor.

Entretanto, os estudos realizados para a elaboração deste artigo mostram que custos na área pública, incluindo a saúde, ainda é um tema pouco abordado.

O tema se justifica pela necessidade de publicações a respeito e pela urgência em melhorar o gerenciamento das organizações governamentais. A Lei 
no 101/2000 (Lei de Responsabilidade Fiscal), que veio impor normas mais rígidas para a administração pública com o objetivo de contribuir na questão da eficiência e da moralidade, em seu art. 50 exige que a administração pública mantenha sistemas de custos; entretanto, até o presente momento, não se sabe muito a respeito do cumprimento dessa norma legal. O baixo índice de publicações a respeito deixa os administradores das organizações públicas sem informações e técnicas suficientes para dar o devido cumprimento à lei.

Não bastando a necessidade da gestão de custos no âmbito governamental em geral, na área da saúde a situação não é diferente, por ser bastante complexa. Composta por vários tipos de procedimentos e atividades e inúmeros empreendimentos realizados dentro de uma única organização, possui características muito singulares, o que torna o trabalho de apuração de custos uma tarefa desafiadora.

Assim, procurou-se identificar, neste artigo, como é o uso das informações de custos na gestão das 20 secretarias municipais da saúde do estado de Santa Catarina que mais receberam verbas do governo federal durante o ano de 2004. Com isso pretende-se trazer mais informações a respeito do assunto no âmbito das secretarias municipais da saúde, que são órgãos públicos vinculados à administração direta e prestam à comunidade uma série de serviços de saúde. Pretende-se mostrar como é o uso e qual a importância da gestão de custos nesses órgãos, na visão de seus gestores.

\section{Revisão da literatura}

Como as secretarias municipais da saúde são organizações públicas que atuam na área da saúde, nesta seção procurou-se enfocar principalmente dois assuntos que fazem parte do tema deste artigo e que possuem poucas publicações a respeito: a gestão de custos na área pública e na área da saúde, com ênfase na saúde pública.

\section{A administração da saúde pública no Brasil}

Em seu sentido mais abrangente, a saúde é resultante, entre outras, das condições de habitação, alimentação, educação, renda, meio ambiente, trabalho, transporte, emprego, lazer, liberdade, acesso e posse de terra, acesso a serviços de saúde. Esse conceito foi definido na VIII Conferência Nacional de Saúde, que foi precedida de um amplo debate e pré-conferências (Santa Catarina, 2002). 
Após a Constituição Federal de 1988, o poder público passou a ter um papel importante na saúde dos cidadãos brasileiros. Atualmente a saúde pública pode ser entendida sob dois aspectos (Santa Catarina, 2002:13):

v no que diz respeito à função pública, a saúde é direito de todos e dever do Estado como oferta de serviços e ações de promoção, proteção e recuperação;

v no que diz respeito às ações de preservação da saúde como dever do cidadão, da sociedade, das empresas e da família por meio de hábitos e atitudes de promoção da saúde.

Tal conceituação estabeleceu que o Estado deve proporcionar o acesso à saúde a todos os cidadãos brasileiros, sem necessidade de contribuição de qualquer tipo, abrangendo inclusive a recuperação da saúde por meio dos atendimentos médicos, exames e tratamentos.

Dois anos depois de promulgada a Constituição Federal de 1988, surgiu a Lei no 8.080, de 19 de setembro de 1990, que criou o SUS (Sistema Único de Saúde) e que norteia sua implantação até o momento da realização deste artigo.

Art. $4^{\circ} \mathrm{O}$ conjunto de ações e serviços de saúde, prestados por órgãos e instituições públicas federais, estaduais e municipais, da administração direta e indireta e das fundações mantidas pelo poder público, constitui o Sistema Único de Saúde - SUS.

(Lei no 8.080/90)

Nesse período os serviços de saúde pública no Brasil foram descentralizados e municipalizados. Com isso, os municípios, através das secretarias municipais da saúde, ganharam a responsabilidade de definir e gerir as ações e serviços de saúde, a possibilidade de controle da sociedade sobre a responsabilidade dos gestores (prefeito e secretário municipal da saúde) e a efetiva participação social na formulação de estratégias e ações locais de saúde, se transformando no principal agente de saúde nos municípios.

Embora se use o termo "municipalização", o que houve na realidade foi uma união de forças entre os governos federal, estadual e municipal, que passaram a compartilhar recursos humanos, equipamentos e edifícios, montando uma estrutura única com a prerrogativa constitucional de atender a todos os cidadãos brasileiros, tendo as prefeituras municipais como comandantes diretas, assessoradas e financiadas, em parte, pelos outros dois níveis de governo. 
Ao SUS cabe não somente a prestação de serviços de atendimento médico, odontológico ou de enfermagem, mas também a formulação de uma política de promoção e proteção da saúde pública, envolvendo uma série de atividades como os programas para a redução do risco de doenças, fiscalização sanitária, epidemiológica, da saúde do trabalhador, de alimentos, remédios etc. (Santa Catarina, 2002).

Na esfera municipal, cabe aos gestores do SUS o planejamento e a execução dos serviços de saúde ao cidadão; já nas esferas estadual e federal, cabe-lhes a promoção da descentralização da saúde, prestar apoio técnico e financeiro aos municípios e identificar fatores que influenciem a saúde pública, em suas competências (Santa Catarina, 2002).

A gestão do SUS é única, de acordo com o inciso I, do art. 198 da Constituição Federal, e exercida em cada esfera de governo, tendo como referência no âmbito municipal o secretário municipal de saúde.

De acordo com o manual de informações básicas para gestores do SUS, as funções que, no âmbito dos municípios, se enquadram como tais são: secretário municipal de saúde, diretores da Secretaria Municipal de Saúde, gerentes de unidades básicas e chefias de postos de saúde. O papel dos gestores do SUS na esfera municipal é o de planejar, executar e avaliar as ações de promoção, proteção e recuperação da saúde (Santa Catarina, 2002:23).

O SUS é financiado conjuntamente pelas três esferas de governo: federal, estadual e municipal, com recursos oriundos de seus orçamentos da seguridade social e fiscal. Os recursos para a saúde, repassados pelo Tesouro Nacional e Seguridade Social, geridos pelo Ministério da Saúde, são divididos em duas partes: uma é retida para o custeio e investimento das ações federais e a outra é repassada às secretarias de saúde estaduais e municipais, de acordo com os critérios previamente definidos em função da população, necessidades de saúde e rede assistencial. Essa transferência pode ser feita mediante convênios, pagamentos diretos a prestadores e/ou transferências fundo a fundo.

O Fundo Municipal de Saúde (FMS) poderá ser provido por recursos repassados pelas esferas federal e estadual, além de receitas obtidas através de outros convênios e referentes a taxas de fiscalização em saúde, conforme determinado pela Constituição Federal, Lei no 8.080/90 e Lei no 8.142/90.

As mesmas leis determinam a estrutura do SUS (Sistema Único de Saúde), onde as secretarias municipais de saúde são os agentes executores das atividades de saúde e atuam através da criação e manutenção de atividades de atendimento médico, odontológico, de enfermagem, da distribuição de medicamentos, de programas de saúde etc. 
O Conasems (2005) informou no documento de teses e plano de ação que o gasto público em saúde no Brasil é de U\$ 125 habitante/ano, o que equivale a aproximadamente $\mathrm{R} \$ 300$ em valores de junho/2005. Esse valor corresponde a cerca de $42 \%$ do gasto total em saúde - os $58 \%$ restantes correspondem ao gasto do setor privado - e ainda assim o financiamento público é insuficiente.

Em entrevista concedida à Revista do Conasems, o médico Silvio Fernandes (2005:9), presidente daquele conselho, deu ênfase ao fato de o processo de descentralização ter ocorrido sem o respectivo financiamento: "tivemos um processo de descentralização ocorrendo sem que a transferência de responsabilidades para os municípios fosse acompanhada de recursos suficientes".

$\mathrm{Na}$ mesma entrevista, Silvio Fernandes comentou ainda que, embora haja falta de recursos, não quer dizer que não existam ineficiência e desperdício; eles existem e devem ser combatidos. Entretanto, o mesmo citou que não são mais relevantes do que em outros setores da administração pública.

Essas questões mostram o quanto é importante pesquisar formas da contabilidade de custos para ajudar a administração da saúde pública a evitar algumas ineficiências e principalmente desperdícios, proporcionando um gasto com maior eficiência, podendo-se realizar mais atividades e atender mais pessoas com a mesma quantidade de recursos.

\section{Gestão de custos na administração pública}

A contabilidade vem sendo utilizada há muito tempo para registrar os fatos e apresentar informações para a tomada de decisão. Desde a revolução industrial e durante todo o século XX ela ganhou força e desenvolveu ramificações, como a contabilidade gerencial e a contabilidade de custos.

Com o passar do tempo, devido ao crescimento das indústrias e com o consequente aumento da distância entre administrador, ativos e pessoas administradas, a contabilidade de custos passou a ser encarada como uma eficiente forma de auxílio no desempenho de uma nova missão: a gerencial. No seu novo campo, a contabilidade de custos tem duas funções relevantes: o auxílio ao controle e a ajuda às tomadas de decisões. Recentemente ela vem sendo utilizada em outras áreas, além da industrial, como o comércio, em instituições financeiras, na área de prestação de serviços, em entidades sem fins lucrativos e na área governamental (Martins, 2003).

Hoje, não somente empresas industriais passaram a utilizar a gestão de custos, mas também organizações na área de prestação de serviços, comér- 
cio e inclusive organizações sem fins lucrativos, tais como hospitais, escolas, bibliotecas, museus e agências governamentais, que passaram a utilizar informações da contabilidade de custos. Os gestores e contadores dessas organizações têm muito em comum com suas contrapartes em organizações com fins lucrativos porque há dinheiro a ser ganho e gasto, orçamentos a serem preparados e observados, a necessidade de sistemas de controles e a obrigação de usar os recursos sabiamente (Horngren, 2004).

A análise das publicações existentes em alguns periódicos A e B do sistema Qualis, na área ciências sociais aplicadas, e nos congressos Enanpad e Congresso Brasileiro de Custos no período de 2000 a 2004 mostrou que são poucos os artigos científicos divulgados a respeito da aplicação das técnicas de gestão de custos na área pública.

$\mathrm{Na}$ análise de 5.839 artigos em 14 periódicos e três congressos, foram encontrados 71 artigos que tratam de custos na área pública. Destes, 54 foram encontrados no Congresso Brasileiro de Custos, o que representa 76\%. No Congresso USP foram encontrados oito, o que representa 11\%, no Enanpad foram encontrados sete artigos, o que representa 10\%; os dois artigos restantes foram encontrados na Revista Brasileira de Economia e na Revista de Administração Pública respectivamente. Em relação aos periódicos, 12, dos 14 analisados, não possuem artigos publicados que tratem da gestão de custos na área pública.

Segue uma análise simplificada do conteúdo dos artigos sobre custos na área pública encontrados:

v nove são na área da educação, com sete sobre custos em universidades públicas;

- oito são aplicações realizadas em empresas públicas, sendo sete em empresas do setor elétrico, como usinas e transmissoras de energia elétrica;

v vinte artigos tratam sobre custos na área da saúde pública, sendo 16 sobre propostas, técnicas e análises realizadas em hospitais públicos;

v os 34 artigos restantes tratam de discussões teóricas a respeito da importância da realização da gestão de custos na área pública em geral, propostas de técnicas a serem aplicadas, formas de redução de custos e análises de custos realizadas em organizações públicas. Destes, sete artigos são voltados especificamente para a gestão de custos no âmbito municipal.

Na sequência, apresentam-se algumas considerações a respeito da gestão de custos na área pública, baseadas em alguns dos artigos mencionados acima 
e também em demais publicações encontradas em outros veículos de divulgação científica, como a Escola Nacional de Administração Pública, Tribunal de Contas da União, Revista do Serviço Público, Revista Brasileira de Contabilidade, Informe-se do BNDES e Congresso USP de Controladoria e Contabilidade.

A Lei de Responsabilidade Fiscal (Lei Complementar no 101, de 4 de maio de 2000, que institui normas de finanças públicas voltadas para a responsabilidade fiscal, em seu $\S 3^{\circ}$ do art. 50 estabelece: "A administração pública manterá sistemas de custos que permitam a avaliação e o acompanhamento da gestão orçamentária, financeira e patrimonial" (o grifo é nosso).

A Constituição Federal também reforça a ideia de uma administração pública gerencial quando menciona em seu art. 37 que a administração pública obedecerá, entre outros, ao princípio da eficiência, e em seu art. 70 segundo o qual deverá obedecer ao princípio da economicidade (Constituição Federal, 1988).

Entretanto, nota-se uma lacuna na área das ciências sociais, no que diz respeito a estudos, pesquisas e publicações sobre gestão de custos na esfera governamental e, como consequência disso, aplicações práticas, se existem, são pouco divulgadas.

Naturalmente, a exigência legal surgiu da necessidade, porém o problema enfrentado é que, embora haja exigência legal, a questão dos custos na administração pública é um assunto pouco estudado e realizado.

Com base nas publicações encontradas, procura-se mostrar a necessidade e a importância da gestão de custos para a administração pública.

Nas últimas duas décadas, surgiu o conceito da administração pública gerencial, contrapondo-se ao modelo burocrático que tem vigorado desde a Revolução Industrial. Nesta reforma, procura-se realizar uma administração pública voltada para o cidadão como cliente, com foco na eficiência e eficácia, na ética e na transparência, na gestão dos recursos públicos com responsabilidade fiscal, na busca proativa de resultados, com a estratégia voltada para a definição precisa dos objetivos que o administrador público deverá atingir em sua unidade, para a garantia de autonomia do administrador na gestão dos recursos humanos, materiais e financeiros e para a cobrança de resultados $a$ posteriori (Silva; Drumond, 2004).

Atualmente o Estado se apresenta como uma grande estrutura, que funciona de forma burocrática, hierarquizada, voltada mais para o cumprimento das exigências legais do que para o atendimento com qualidade das necessidades dos cidadãos e, no caso do Brasil, com uma série de problemas sociais a serem enfrentados.

Os desafios existem em função da alta demanda pela necessidade de serviços públicos e em função da escassez de recursos para supri-la (Alonso, 1999 
- grifo nosso). Este autor, que realizou um trabalho que contribui bastante para a discussão do assunto, e que vem sendo muito citado nos trabalhos a respeito deste tema, comenta a respeito das dificuldades enfrentadas pelo Estado a partir dos anos 1980, em função da intensificação da crise fiscal, da exposição da economia nacional à competição internacional e da impossibilidade de aumentar impostos, e que diante desta situação a opção foi realizar contenção de despesas para manter o equilíbrio. O mesmo autor menciona que organismos internacionais como o Banco Mundial e o Fundo Monetário Internacional (FMI) vêm enfatizando a qualidade do gasto público ao invés de simplesmente realizar o corte de despesas.

\section{O problema de saber onde e como cortar os gastos}

A necessidade da contenção de despesas leva a um corte de gastos, entretanto o problema é como e onde cortar gastos sem perda da quantidade e da qualidade dos serviços prestados. O correto seria o corte dos desperdícios realizados e não um corte em recursos que são necessários à manutenção da quantidade e da qualidade dos serviços prestados. Wiemer e Ribeiro (2004) comentam que "o governo sempre soube o quanto precisaria gastar, mas nunca soube ao certo como e onde deveria efetuá-lo". Comentam também que o corte de despesas compromete a qualidade do serviço público, e consequentemente, a competitividade da economia brasileira e das empresas.

\section{A necessidade da mudança}

Em função dessas necessidades, a administração pública deve se modernizar e adequar os seus sistemas de informações para que possam proporcionar uma tomada de decisões que venha a melhorar a qualidade de vida da população com economicidade.

\section{O papel da gestão de custos}

Assim, tem-se observado nos artigos publicados atualmente que a contabilidade de custos pode ser um componente importante dos sistemas de informações, e que ela pode ajudar a fornecer aos administradores públicos melhores informações para a tomada de decisão. 
O que se debate é que o foco deve estar na qualidade do gasto, porém a contabilidade pública não apresenta informações gerenciais que supram essa necessidade, e esse é um dos pontos onde a gestão de custos pode auxiliar.

$\mathrm{O}$ auxílio à gerência é um dos pontos fortes da gestão de custos. Ela pode auxiliar os administradores públicos na tomada de decisão e apresentar vários outros tipos de informações, que poderão ser elaboradas com a evolução proveniente da sua aplicação nos órgãos públicos e da discussão em artigos publicados.

Silva (1997), em um trabalho realizado com o objetivo de dar uma contribuição ao estudo para implantação de uma contabilidade de custos na administração pública, relata que os gestores públicos, ao se depararem com déficit nas contas públicas, tentam solucionar o problema de três formas: lutar por uma reforma constitucional para arrecadar mais; aumentar a alíquota dos impostos; ou realizar empréstimos.

Nesses casos, com o aumento dos custos, procura-se uma forma de se conseguir mais receitas, quando o ideal seria tentar reduzir ou racionalizar as despesas (Silva, 1997). Diante de tal situação, o autor coloca:

Como o objetivo do setor público não é a obtenção de lucros, a busca pelo controle dos custos estaria mais voltada para uma melhor aplicação dos recursos, o que iria promover uma distribuição mais eficiente dos gastos públicos, de forma a atender o maior número de "clientes".

(Pereira e Silva, 2003)

Afonso (2000) informa que muitos administradores públicos apresentam projetos implantados em suas gestões, relatando o quanto executaram em um determinado período, preocupando-se em mostrar o volume de obras realizadas, de populações atendidas etc. Dificilmente explicam se um projeto foi realizado com baixos custos e qualidade adequada.

Miola (2001) critica que é necessário ter "vontade política" para que sejam implantados os sistemas de custos.

Alonso (1999), ao comentar a mudança do modelo de gestão tradicional ou burocrático para o gerencial na administração pública internacional, afirma que o modelo tradicional enfatiza os controles formais e o estrito cumprimento da lei, enquanto os novos modelos enfatizam a melhoria do desempenho e dos resultados. Porém, o mesmo autor alerta que, para realizar-se uma administração pública voltada para resultados, o perfil dos gerentes e os sistemas de informações devem estar alinhados com esta orientação, e estes 
sistemas devem poder contar com uma informação gerencial mais refinada que a despesa: os custos.

A gestão de custos na administração pública ainda é um assunto a ser bastante discutido e estudado; ainda está longe de se chegar a um consenso a respeito. Porém, a exigência legal está vigorando, o que torna a discussão necessária e urgente.

\section{Gestão de custos na área da saúde pública}

Na pesquisa sobre artigos publicados, foram utilizados os mesmos veículos de publicação mostrados no item que trata de gestão de custos na administração pública, ou seja, foram analisadas as publicações existentes em alguns periódicos A e B do sistema Qualis, na área de ciências sociais aplicadas I e nos congressos Enanpad e Congresso Brasileiro de Custos no período de 2000 a 2004.

Dos 5.839 artigos publicados analisados, foram encontrados 179 artigos que tratam de gestão na área da saúde; desses, apenas 21 artigos tratam da gestão de custos na área da saúde pública.

Os maiores meios de divulgação de artigos na área da saúde são: Congresso Brasileiro de Custos, Enanpad e Revista de Administração Pública. Desses, apenas o Congresso Brasileiro de Custos apresentou uma quantidade maior de artigos sobre custos na saúde pública.

Dos 21 artigos sobre custos em saúde pública encontrados, destaca-se que 17 tratam da gestão de custos em hospitais públicos, três da gestão de custos em laboratórios públicos e um do custo do PSF (Programa de Saúde da Família) realizado pelo SUS.

Dos 17 artigos sobre custos em hospitais públicos, oito tratam da aplicação do custeio $\mathrm{ABC}$ nesses órgãos.

Os únicos artigos que tratam da gestão de custos em atividades realizadas por secretarias municipais de saúde são:

v dois artigos que tratam da gestão de custos em laboratórios de análises clínicas vinculados às secretarias municipais de saúde;

v um artigo que trata do custo do PSF (Programa de Saúde da Família), mantido pelo SUS, administrado por uma secretaria da saúde.

Foram feitas algumas considerações a respeito da gestão da área da saúde, baseadas nos artigos mencionados e também em demais veículos de publicação científica. 
Há a necessidade de aprimoramento na gestão de organizações em geral em todo o mundo. Acompanhando o crescimento global, as organizações crescem e expandem-se de forma a tornarem-se cada vez mais complexas.

Carpintéro (1999) menciona que nos últimos anos foram intensificadas as referências sobre custos na área da saúde, e isso ocorreu por influência de vários aspectos como: os crescentes gastos públicos na área; os problemas relacionados ao financiamento dos gastos; a grande necessidade do controle e do uso das informações de custos para tomada de decisão; a importância do gerenciamento na área da saúde; a pequena disseminação de métodos adequados de apuração e mensuração de custos e de análise e escolha de programas, e estabelecimento de políticas para a área.

As organizações que atuam na área da saúde, com o crescimento e aprimoramento desta área, também tiveram a necessidade de se aprimorar e acompanhar o desenvolvimento técnico e tecnológico ocorrido. Para que se possa acompanhar tal crescimento, há a necessidade de os profissionais da área das ciências sociais aplicadas - das ciências da administração, das ciências contábeis e das ciências econômicas - dirigirem estudos e pesquisas para essa área.

A saúde é uma área bastante complexa, composta por vários tipos de procedimentos e atividades, o que torna a sua administração uma tarefa desafiadora.

Um dos principais problemas enfrentados na gestão das organizações de saúde é que, normalmente, essas unidades são administradas por profissionais da área da saúde, muitas vezes médicos, que não têm conhecimento técnico suficiente para lidar com as questões administrativas complexas, existentes nesse tipo de organização (Cecílio, 1997; Gonçalves, 1998).

Quinto Neto (1998) aponta que o conflito entre aspectos gerenciais e clínicos, em grande parte, é decorrente das formações acadêmicas diversas. Os administradores respondem pela viabilidade econômica das organizações de saúde, e os médicos colocam a atenção na prática da boa assistência clínica aos pacientes.

Quando se pensa na área da saúde, o que vem em mente são os hospitais com suas estruturas complexas e complicadas. Como foi observado, foram encontrados 16 artigos sobre custos em organizações públicas hospitalares; destes, oito tratam da implantação do custeio ABC. Nos artigos analisados, nota-se a preocupação com a realização da gestão de custos nessas organizações e aponta-se que este é um grande desafio a ser superado.

Beulke e Bertó (1997) afirmam que as características dessa área tornam a tarefa complexa, diante dos inúmeros empreendimentos realizados dentro 
de uma única organização, e também que a maior parte das instituições de saúde no país desconhece sua estrutura de custos.

Porém, as organizações de saúde não se resumem a hospitais. Existem também as clínicas médicas em que são realizados exames, consultas e pequenos tratamentos em alguns casos; laboratórios de análises onde são realizados, entre outros, exames do tipo urina, sangue e fezes; laboratórios de raio-x; farmácias; enfim, todas as organizações que fornecem materiais e serviços na área da saúde.

\section{Metodologia}

A metodologia utilizada foi pesquisa de campo com abordagem predominantemente qualitativa com aporte quantitativo. O pesquisador realizou quatro pré-testes com gestores das secretarias de saúde dos municípios de Balneário Camboriú e Itajaí durante o primeiro semestre do ano de 2005. Após algumas correções e adequações a pesquisa foi aplicada durante o segundo semestre de 2005, caracterizando-se assim por possuir um corte longitudinal.

As questões que nortearam a presente pesquisa são: como se caracteriza o perfil dos gestores das secretarias municipais de saúde pesquisadas? Existem sistemas de custos implantados nas secretarias? Qual é a percepção dos gestores dessas secretarias sobre a importância das informações de custos na gestão das mesmas? Quais as informações de custos que são utilizadas por esses gestores?

Foram selecionadas as 20 secretarias municipais de saúde do estado de Santa Catarina que mais receberam verbas federais durante o ano de 2004, conforme dados do Datasus (2005). Das 20 secretarias municipais de saúde selecionadas, 18 participaram da pesquisa.

Foi do entendimento do pesquisador, em conjunto com o seu orientador, que 18 secretarias municipais de saúde pesquisadas são um bom número para a pesquisa, principalmente em função do tempo para a realização e do caráter preliminar da mesma. A seleção limita-se ao estado de Santa Catarina em função de ser o estado onde o pesquisador reside e, assim, deixar a pesquisa menos onerosa. Não chamamos a seleção de amostra por não se pretender aplicar os resultados da pesquisa às demais secretarias de saúde não pesquisadas.

Utilizou-se o critério "verbas recebidas do governo federal" em função da pesquisa, por seu objetivo maior tratar-se da verificação da existência de informações e/ou sistemas de custos nesses órgãos. Como são informações 
financeiras, utilizou-se, dessa forma, um critério também financeiro para selecionar as secretarias municipais da saúde pesquisadas.

A informação sobre o montante de verbas repassadas aos municípios foi obtida junto ao Datasus, que é o órgão de processamento de dados e informática do SUS.

Os participantes da pesquisa foram pessoas ocupantes de cargos administrativos nas secretarias municipais de saúde pesquisadas, como diretores administrativos/financeiros, secretários de saúde e demais cargos relacionados com a administração desses órgãos.

O instrumento utilizado para coleta dos dados foi um questionário aplicado pelo próprio pesquisador, contendo perguntas abertas e fechadas, e composto de quatro partes: a primeira parte procurou investigar o perfil dos participantes da pesquisa; a segunda parte, a estrutura das secretarias municipais de saúde pesquisadas; a terceira parte da pesquisa procurou investigar a existência de informações financeiras básicas, de informações sobre a produção, de informações de custos e a percepção dos participantes da pesquisa quanto à importância do uso dessas informações na gestão das secretarias municipais da saúde pesquisadas; na quarta e última parte, foram elencadas questões diversas a respeito da gestão dessas secretarias, com o intuito de dar alguma base para a elaboração de um sistema de custos para esses órgãos. Procurou-se redigir as questões com uma linguagem simples e explicativa, sem utilizar muitos termos técnicos da área da administração ou da contabilidade, para que as mesmas pudessem ser entendidas facilmente, evitando assim um entendimento diferente entre os participantes. Richardson (1999) define que um questionário pode ser aplicado por meio do contato direto, pelo próprio pesquisador ou por pessoas especialmente treinadas por ele. Dessa forma, o autor menciona que há menos possibilidades de os participantes da pesquisa não responderem ao questionário ou deixarem algumas perguntas em branco.

A aplicação do questionário foi realizada pelo próprio pesquisador da seguinte forma: foi feito um contato telefônico inicial com cada secretaria de saúde no sentido de verificar a existência de uma pessoa ocupante de um cargo de diretor ou gerente administrativo que fosse responsável pela administração da secretaria. Após a indicação, foi realizado um contato com tal pessoa e averiguada sua disponibilidade para a participação na pesquisa. Na sequência, foram marcados data, hora e local da entrevista. O pesquisador foi até o município e aplicou o questionário de forma oral, porém dando uma cópia ao participante para que ele também lesse cada questão realizada. A cada aplicação o pesquisador tomou o cuidado de realizar as questões da mesma forma, 
com mesmo tom de voz. Quando os participantes da pesquisa não entendiam a questão ou a entendiam de outra forma, o pesquisador explicava detalhadamente o objetivo e o propósito da realização da mesma, para um melhor entendimento. As respostas fornecidas pelos participantes foram anotadas no próprio questionário pelo pesquisador. Cada aplicação teve duração média de aproximadamente uma hora. Em alguns casos, devido à impossibilidade do participante da pesquisa em realizar a entrevista, não foi possível fazê-la. Nesses casos, em função do tempo disponível e do dispêndio financeiro para realizar novamente a viagem, o pesquisador verificou a possibilidade de outra pessoa ligada à administração da secretaria de saúde participar da pesquisa. Na ocorrência desse fato, em dois municípios isso não foi possível; logo, a entrevista não foi realizada.

Uma das limitações da pesquisa foi que o ano de 2005 foi o primeiro ano de mandato dos governantes eleitos em 2004. Por esse motivo muitos dos participantes da pesquisa foram nomeados no início de 2005 para ocupar seus cargos, motivo pelo qual os mesmos tinham pouco tempo de experiência na função, o que pode ter feito com que algumas respostas tenham sido fornecidas sem muita convicção. Entretanto, por já se ter previamente esse conhecimento, procurou-se realizar a pesquisa no segundo semestre de 2005, para que os participantes tivessem pelo menos mais seis meses de experiência na função. Outro fato que ameniza essa limitação é o de ter sido constatado na pesquisa que os participantes, embora tivessem pouco tempo de experiência na função exercida, em sua maioria eram pessoas com bastante tempo de experiência em saúde pública.

Outra limitação foi o fato de haver pouco material para estudo sobre o tema a ser explorado, o que fez com que a fundamentação teórica não fosse mais profunda e que, por sua vez, não desse uma boa base para a elaboração das questões. Estas tiveram, então, que ser realizadas baseando-se mais no conhecimento geral da contabilidade de custos para organizações privadas e no bom senso e na experiência do pesquisador em administração de secretarias municipais de saúde, já que o mesmo é colaborador administrativo na Secretaria de Saúde do Município de Balneário Camboriú, onde é responsável pelo desenvolvimento da contabilidade de custos. Assim, foi feito um estudo preliminar, exploratório, buscando realizar um levantamento tanto bibliográfico quanto empírico de como se encontra a questão da gestão de custos na saúde pública, considerando a quantidade de secretarias municipais de saúde selecionadas, para que esta pesquisa pudesse contribuir com estudos futuros a respeito do tema proposto. 


\section{Apresentação e análise dos resultados}

Aqui são apresentados os resultados da pesquisa obtidos por meio das entrevistas realizadas, bem como as análises correspondentes.

\section{Os municípios pesquisados}

Os municípios pesquisados foram: Joinville, Blumenau, Criciúma, Chapecó, Lages, Itajaí, Jaraguá do Sul, Rio do Sul, Florianópolis, Balneário Camboriú, Brusque, Concórdia, São José, São Bento do Sul, Palhoça, Tubarão, Laguna, Imbituba, Içara e Rio Negrinho. Dos 20 municípios selecionados, em dois não foi possível realizar a pesquisa: Tubarão e Imbituba. Participaram da pesquisa 18 municípios.

O quadro 1 mostra o resumo do perfil dos entrevistados, para uma melhor visualização das respostas obtidas.

$$
\text { Quadro } 1
$$

Resumo do perfil dos entrevistados

\begin{tabular}{|lll|}
\hline Ordem & \multicolumn{1}{c|}{ Questões realizadas } & \multicolumn{1}{c|}{ Respostas obtidas } \\
\hline 1 & Função exercida pelo entrevistado & $\begin{array}{l}\text { Todas relacionadas com a administração das } \\
\text { secretarias municipais de saúde }\end{array}$ \\
2 & Tempo de experiência nesta função & $67 \%$ com menos de um ano \\
3 & Tempo de experiência em saúde pública & $83 \%$ com mais de cinco anos \\
4 & Formação do entrevistado & $38 \%$ com formação na área de saúde \\
& & $27 \%$ com formação na área de gestão \\
& & $17 \%$ com formação em outras áreas \\
& & $16,7 \%$ sem formação superior \\
5 & Realização de curso de pós-graduação & $54 \%$ têm especialização ou mestrado \\
& & completos ou em curso \\
6 & Acesso às informações da contabilidade & Apenas um declarou não ter acesso \\
& do FMS & \\
7 & Informações contábeis mais acessadas & Ocorreram 22 citações para informações do \\
& & $\begin{array}{l}\text { orçamento e relatórios de despesas, o que } \\
\text { representa } 71 \% \text { das respostas }\end{array}$ \\
\hline
\end{tabular}

Ao se analisar o quadro do perfil dos entrevistados, pode-se observar que todos têm condições de fornecer respostas fidedignas para a pesquisa, 
uma vez que todos ocupam cargos relacionados à administração das secretarias municipais de saúde pesquisadas e possuem uma boa experiência em saúde pública, embora ocupem os cargos mencionados há pouco tempo. Quanto ao grau de instrução, quase todos possuem curso superior e grande parte deles realiza ou realizou cursos de pós-graduação. Apenas um dos entrevistados declarou não ter acesso às informações da contabilidade do Fundo Municipal da Saúde.

\section{Dados preliminares das secretarias municipais da saúde}

Esta parte da pesquisa procurou identificar alguns dados importantes da estrutura administrativa e do funcionamento das secretarias municipais de saúde, que poderão dar uma ideia do tamanho e da complexidade desses órgãos.

\section{Quadro 2 \\ Resumo das informações sobre a estrutura das secretarias municipais da saúde pesquisadas}

\begin{tabular}{|c|c|c|}
\hline Ordem & Questão & Resumo das respostas \\
\hline 1 & $\begin{array}{l}\text { Cargo que realiza a administração } \\
\text { financeira }\end{array}$ & $\begin{array}{l}\text { Sete dir./gerentes administrativo-financeiros } \\
\text { Cinco cargos criados especialmente para } \\
\text { administraçãa financeira como gestor/coordenador } \\
\text { do FMS e chefe/gerente do financeiro } \\
\text { Quatro contadores ou diretores de contabilidade } \\
\text { Um funcionário comum, sem cargo de chefia } \\
\text { Um não possui cargo/pessoa espećfica }\end{array}$ \\
\hline 2 & $\begin{array}{l}\text { Local onde é realizada a contabilidade } \\
\text { do FMS }\end{array}$ & $\begin{array}{l}\text { dez nas dependências da secretaria de saúde, } \\
\text { desvinculada da prefeitura } \\
\text { Oito realizadas nas dependências da prefeitura pelos } \\
\text { mesmos profissionais que realizam a contabilidade } \\
\text { do município }\end{array}$ \\
\hline 3 & $\begin{array}{l}\text { Quantidade de funcionários das } \\
\text { secretarias municipais da saúde } \\
\text { pesquisadas }\end{array}$ & $\begin{array}{l}\text { dez com mais de } 600 \\
\text { Oito com menos de } 600\end{array}$ \\
\hline 4 & Existência da contabilidade de custos & $\begin{array}{l}\text { Dois declararam a existência. Os demais informaram } \\
\text { tentativas e algumas informações esporádicas }\end{array}$ \\
\hline 5 & $\begin{array}{l}\text { Pretensão de implantação da } \\
\text { contabilidade de custos }\end{array}$ & $\begin{array}{l}\text { Sete afirmaram positivamente } \\
\text { Nove afirmaram que não existe projeto ou } \\
\text { pretensão }\end{array}$ \\
\hline 6 & Existência da controladoria interna & $\begin{array}{l}\text { Sim }-14 \\
\text { Não - quatro }\end{array}$ \\
\hline
\end{tabular}




\begin{tabular}{|c|c|c|}
\hline Ordem & Questão & Resumo das respostas \\
\hline 7 & $\begin{array}{l}\text { Quantidade de unidades de saúde } \\
\text { administradas }\end{array}$ & $\begin{array}{l}\text { dez possuem até } 20 \text { unidades de saúde } \\
\text { Oito com mais de } 20 \text { unidades, sendo quatro com } \\
\text { mais de } 50 \text { unidades }\end{array}$ \\
\hline 8 & $\begin{array}{l}\text { Formação do secretário (a) municipal } \\
\text { de saúde }\end{array}$ & $\begin{array}{l}\text { Medicina - } 11 \\
\text { Pedagogia - dois } \\
\text { Odontologia - um } \\
\text { Administração - um } \\
\text { Ciências econômicas - um } \\
\text { Sem formação superior - um }\end{array}$ \\
\hline
\end{tabular}

A parte da pesquisa mostrada no quadro 2 apontou que existe uma grande diferença entre a estrutura das secretarias municipais de saúde pesquisadas. A menor secretaria apresenta uma estrutura administrativa com mais de 200 funcionários e 11 unidades de saúde externas, enquanto a maior possui mais de 2 mil funcionários e mais de 50 unidades de saúde.

Mesmo a menor secretaria de saúde pesquisada apresenta estrutura administrativa grande, considerando ainda que, somente em verbas recebidas do governo federal, recebe aproximadamente $\mathrm{R} \$ 2,5$ milhões por ano.

Serão apresentados alguns pontos positivos levantados na pesquisa que podem justificar a implantação da contabilidade de custos nas secretarias de saúde pesquisadas e pontos negativos que podem dificultar tal implantação.

Pontos positivos:

v cargo que realiza a administração financeira - apenas uma não possui um cargo específico que realize a administração financeira. Este é um ponto positivo, pois a existência de um cargo como esse pode facilitar a implementação da contabilidade de custos;

- grande quantidade de funcionários - a menor apresenta mais de 200 funcionários. A folha de pagamento com seus encargos representa geralmente a maior parte do orçamento; a contabilidade de custos pode ajudar a controlar melhor os gastos com pessoal;

- pretensão de implantar a contabilidade de custos - sete dos 18 participantes afirmaram a existência dessa pretensão. Isso é um fato positivo, pois mostra a necessidade já detectada;

- existência da controladoria interna - como já mencionado na fundamentação teórica deste artigo, a contabilidade de custos pode ajudar bastante o processo de controladoria interna dos órgãos públicos; 
- grande quantidade de unidades de saúde - a existência dessas unidades externas requer conhecimentos dos custos de manutenção, pois se o município tem pretensões de ampliar a quantidade dessas unidades deve conhecer o custo de manutenção das mesmas. Porém, em uma questão que verifica a existência dessa informação, apenas cinco informaram possuir, mesmo que esporadicamente.

Pontos negativos:

- local onde é realizada a contabilidade do FMS - para a implantação da contabilidade de custos é importante que a contabilidade do FMS seja realizada nas dependências da secretaria de saúde;

v formação do(a) secretário(a) municipal de saúde - como apenas em dois municípios o(a) secretário(a) municipal de saúde tem formação na área de gestão, esse pode ser um dos motivos para a não existência da contabilidade de custos nas secretarias de saúde pesquisadas. As pessoas que têm formação na área de gestão normalmente apresentam um conhecimento maior sobre o benefício de se ter informações de custos.

\section{Informações financeiras e de custos utilizadas}

O objetivo aqui foi identificar as informações de custos existentes nas secretarias municipais de saúde pesquisadas. Foram realizadas desde questões a respeito de informações básicas sobre receitas e despesas até questões sobre $o$ custo dos serviços prestados. Para tanto, foram selecionadas algumas das informações consideradas mais importantes a respeito dos custos em secretarias municipais de saúde.

Para um resumo das informações de custos pesquisadas, apresenta-se a tabela 1 com o percentual das respostas obtidas nas entrevistas.

Pela tabela 1, pode-se concluir, em relação às informações financeiras básicas, que quase todos os entrevistados declararam ter acesso a essas informações. Destas, somente o percentual de recursos repassados por cada esfera no orçamento por convênio teve um percentual menor $(77,8 \%)$. O restante ficou entre $94 \%$ e $100 \%$.

O mesmo já não acontece com as informações de custos, nas quais somente $5 \%$ a $11 \%$ dos entrevistados declararam que as informações existem nas secretarias municipais de saúde pesquisadas. 
Tabela 1

\section{Resumo das informações de custos existentes}

\begin{tabular}{|c|c|c|c|c|c|c|c|c|c|c|}
\hline \multirow{3}{*}{$\begin{array}{l}\begin{array}{l}\text { Informações de custos } \\
\text { utilizadas }\end{array} \\
1 \text { - Saldo em caixa }\end{array}$} & \multicolumn{6}{|c|}{ Existência da informação } & \multicolumn{4}{|c|}{ Grau de importância } \\
\hline & \multirow{2}{*}{\multicolumn{2}{|c|}{\begin{tabular}{ll}
\multicolumn{1}{c}{$\operatorname{Sim}$} \\
18 & $100,0 \%$
\end{tabular}}} & \multicolumn{2}{|c|}{ Esporadicamente } & \multicolumn{2}{|c|}{ Não } & \multicolumn{2}{|c|}{ É importante } & \multicolumn{2}{|c|}{$\begin{array}{l}\text { Não ajuda } \\
\text { muito }\end{array}$} \\
\hline & & & 0 & $0 \%$ & 0 & $0 \%$ & 18 & $100 \%$ & 0 & $0 \%$ \\
\hline 2 - Dotação orçamentária & 17 & $94,4 \%$ & 0 & $0 \%$ & 1 & $5,6 \%$ & 18 & $100 \%$ & 0 & $0 \%$ \\
\hline 3 - Despesas mensais & 17 & $94,4 \%$ & 0 & $0 \%$ & 1 & $5,6 \%$ & 18 & $100 \%$ & 0 & $0 \%$ \\
\hline $\begin{array}{l}4 \text { - Percentual de } \\
\text { recursos repassados por } \\
\text { cada esfera no orçamento } \\
\text { global }\end{array}$ & 18 & $100,0 \%$ & 0 & $0 \%$ & 0 & $0,0 \%$ & 18 & $100 \%$ & 0 & $0 \%$ \\
\hline $\begin{array}{l}5 \text { - Percentual de } \\
\text { recursos repassados por } \\
\text { cada esfera no orçamento } \\
\text { por convênio }\end{array}$ & 14 & $77,8 \%$ & 1 & $5,6 \%$ & 3 & $16,7 \%$ & 18 & $100 \%$ & 0 & $0 \%$ \\
\hline $\begin{array}{l}6 \text { - Quantidade de } \\
\text { atendimentos realizados } \\
\text { em cada tipo de serviço } \\
\text { prestado }\end{array}$ & 18 & $100 \%$ & 0 & $0 \%$ & 0 & $0 \%$ & 18 & $100 \%$ & 0 & $0 \%$ \\
\hline $\begin{array}{l}7 \text { - Quantidade de } \\
\text { exames solicitados por } \\
\text { profissional }\end{array}$ & 10 & $55,6 \%$ & 2 & $11,1 \%$ & 6 & $33,3 \%$ & 17 & $94,4 \%$ & 1 & $5,6 \%$ \\
\hline 8 - Custo de cada setor & 1 & $5,6 \%$ & 5 & $27,8 \%$ & 12 & $66,7 \%$ & 18 & $100 \%$ & 0 & $0 \%$ \\
\hline $\begin{array}{l}9 \text { - Custo total mensal } \\
\text { das unidades de saúde }\end{array}$ & 1 & $5,6 \%$ & 4 & $22,2 \%$ & 13 & $72,2 \%$ & 18 & $100 \%$ & 0 & 0\% \\
\hline $\begin{array}{l}10 \text { - Custo de cada } \\
\text { atendimento médico }\end{array}$ & 2 & $11,1 \%$ & 4 & $22,2 \%$ & 12 & $66,7 \%$ & 18 & $100 \%$ & 0 & $0 \%$ \\
\hline $\begin{array}{l}11 \text { - Custo de cada } \\
\text { atendimento de } \\
\text { enfermagem }\end{array}$ & 2 & $11,1 \%$ & 1 & $5,6 \%$ & 15 & $83,3 \%$ & 18 & 100\% & 0 & 0\% \\
\hline
\end{tabular}

Quando foi realizada a questão que procurou identificar a existência de um setor responsável por desenvolver a gestão de custos, contabilidade de custos ou contabilidade gerencial ou outra atividade que forneça informações a respeito dos custos da secretaria de saúde de forma detalhada, apenas dois entrevistados afirmaram positivamente. Nas questões que procuraram identificar a existência da informação do custo de cada setor, englobando o custo mensal das unidades 
de saúde e a comparação com a terceirização, apenas um deles informou ter acesso. Isso se justifica em função de o outro ter declarado que a implantação da contabilidade de custos se deu no mesmo ano em que a pesquisa foi realizada, $\mathrm{e}$ que ainda estava em fase de implantação, não produzindo muitas informações.

Quanto às informações referentes aos quantitativos, a quantidade de atendimentos realizados em cada tipo de serviço prestado é uma informação existente em todas (100\%) as secretarias municipais de saúde pesquisadas. Já a quantidade de exames solicitados por profissional é um controle realizado em somente $50 \%$ delas, segundo as respostas dos entrevistados.

Em relação ao grau de importância das informações pesquisadas, grande parte dos entrevistados declarou que quase todas as informações são importantes no processo de gestão das secretarias municipais de saúde pesquisadas. Houve diferença de resposta em apenas duas: a quantidade de exames solicitados por profissional, na qual um entrevistado declarou não ajudar muito na gestão; e dois entrevistados, um é o mesmo da questão anterior, declararam a mesma situação para a comparação com terceirização.

\section{Questões diversas sobre a gestão das secretarias municipais da saúde}

Aqui, foram analisadas algumas questões a respeito da gestão das secretarias municipais de saúde, a fim de verificar alguns pontos onde a contabilidade de custos poderia ajudar esses órgãos no processo de gestão.

Inicialmente a pesquisa procurou identificar se, de acordo com a opinião do entrevistado, a contabilidade pública é eficiente no fornecimento de informações para a tomada de decisão nas secretarias municipais de saúde pesquisadas. Esse questionamento foi feito para verificar se, na opinião dos entrevistados, a contabilidade pública precisaria ou não ser aperfeiçoada para fornecer mais e melhores informações para suprir o processo de tomada de decisões na gestão.

Tabela 2

Opinião sobre a eficiência da contabilidade pública

\begin{tabular}{|ccl|}
\hline Resposta & Quantidade & $\%$ \\
\hline Sim & 4 & 22,2 \\
Não & 14 & 78,8 \\
\hline
\end{tabular}


Esta questão procurou identificar se os órgãos de saúde pesquisados possuem algum documento a respeito do planejamento das suas ações para os próximos três anos de mandato.

Tabela 3

Existência de objetivos para os próximos três anos

\begin{tabular}{|ccc|}
\hline Resposta & Quantidade & $\%$ \\
\hline Sim & 17 & 94,4 \\
Não & 01 & 5,6 \\
\hline
\end{tabular}

Apenas um entrevistado declarou que a secretaria não possui objetivos para os próximos anos de mandato. Os demais declararam que possuem objetivos e eles estão documentados. Grande parte dos entrevistados citou o PPA (Plano Plurianual) e o PMS (Plano Municipal de Saúde), ambos exigidos por lei, como a forma de documentação do planejamento. Embora um entrevistado tenha afirmado não existir objetivos documentados, acredita-se que o mesmo tenha se esquecido do PPA e do PMS ou, talvez, em sua unidade tais documentos existam somente para mero cumprimento legal, sem fazer parte realmente de um planejamento.

Essa questão procurou identificar como é o processo de elaboração do orçamento anual do Fundo Municipal de Saúde. Durante a realização das entrevistas, o entrevistador procurou classificar os processos de três formas, conforme a tabela 4.

Tabela 4

Como é a participação no processo de elaboração do orçamento anual do FMS

\begin{tabular}{|lcc|}
\hline Resposta & Quantidade & $\%$ \\
\hline Participação ampla & 5 & 27,8 \\
Participação restrita & 12 & 66,7 \\
Secretaria de saúde não participa & 1 & 5,6 \\
\hline
\end{tabular}

Os resultados indicam que cinco entrevistados, que representam $27,8 \%$ dos municípios pesquisados, realizam um processo amplo com a participação de diversos membros de diversos setores da secretaria municipal de saúde, inclusive representantes das unidades de saúde. Dois dos cinco municípios 
que indicaram participação ampla informaram ser esse um processo novo que começou em 2005, portanto na elaboração do orçamento do ano de 2006.

Já 12 entrevistados $(66,7 \%)$ declararam que o processo é realizado por um grupo restrito de membros da secretaria municipal de saúde, composto pelo secretário municipal de saúde, alguns de seus assessores e também por membros da prefeitura municipal.

Somente um dos entrevistados $(5,6 \%)$ declarou que o orçamento é elaborado por membros da prefeitura municipal sem a participação do secretário municipal de saúde ou qualquer outro membro da secretaria. Dois dos quatro municípios que indicaram participação ampla informaram que esse é um processo novo que se iniciou em 2005, portanto, na elaboração do orçamento do ano de 2006.

A próxima questão procurou identificar o conhecimento do entrevistado a respeito do texto da Lei de Responsabilidade Fiscal, que indica a obrigatoriedade dos órgãos públicos em manter sistemas de custos.

$$
\text { Tabela } 5
$$

Conhecimento a respeito do art. 50 da Lei de Responsabilidade Fiscal

\begin{tabular}{|lcc|}
\hline Resposta & Quantidade & $\%$ \\
\hline Conheciam & 8 & 44,4 \\
Não conheciam & 10 & 55,6 \\
\hline
\end{tabular}

As respostas indicaram que $55,6 \%$ dos entrevistados já conheciam essa exigência legal e $44,4 \%$ a desconheciam. Naturalmente, o desconhecimento da lei é um dos motivos que colaboram para o não desenvolvimento da contabilidade de custos nas secretarias municipais de saúde. Mas, mesmo com o conhecimento da lei, a sua implantação não é promovida em função de o texto da lei não ter sido regulamentado. Nesse caso, a legislação não deixou claro como deverão ser realizados os sistemas de custos, até quando deverão ser implantados, ou até mesmo o que é entendido por sistemas de custos. Outro motivo também é não haver cobrança, por parte dos tribunais de contas, no que se refere à sua implantação.

As informações de custos podem servir para nutrir o processo de avaliação de gestão de qualquer organização. Identificar as formas de avaliação e fornecer informações de custos tendo em vista tais informações é bastante importante na implantação de qualquer sistema de custos. Essa questão foi realizada para verificar, na opinião dos entrevistados, quais os melhores índices 
para avaliar a gestão da saúde pública em um município, e seus resultados (respostas) poderão servir de base à montagem de um sistemas de custos para secretarias municipais de saúde. A satisfação da população, a redução do índice de doenças no município, a qualidade no atendimento e a resolução dos casos de doenças foram os índices mais citados no processo. Alguns dos índices citados têm relação entre si, como será comentado mais adiante.

Tabela 6

Índices mais citados nas três colocações

\begin{tabular}{|lcc|}
\hline Resposta & Quantidade & $\%$ \\
\hline Satisfação da população & 15 & 27,8 \\
Redução do índice de doenças no município & 12 & 22,2 \\
Qualidade no atendimento & 9 & 16,7 \\
Resolução dos casos de doenças & 9 & 16,7 \\
Aumento da receita & 3 & 5,6 \\
Quantidade de atendimentos & 1 & 1,9 \\
Facilitação do acesso da população à saúde & 1 & 1,9 \\
Criação de programas preventivos & 1 & 1,9 \\
Avaliação de dados epidemiológicos & 1 & 1,9 \\
Cumprimento do Plano Plurianual & 1 & 1,9 \\
Eficiência nos serviços prestados & 1 & 1,9 \\
\hline
\end{tabular}

Na tabela 6, nota-se que os quatro índices mais citados pelos entrevistados foram: a "satisfação da população", a "redução do índice de doenças no município" e a "resolução dos casos de doenças", que obteve um empate com a "qualidade no atendimento". Os demais índices foram citados poucas vezes cada um.

Para facilitar o acesso da população à saúde é preciso, necessariamente, ampliar a quantidade de atendimentos, pois facilitar o acesso é também criar novos mecanismos pelos quais o cliente não tenha que enfrentar tantas dificuldades, burocracias e entraves quando precisar do atendimento.

Pode-se reduzir o índice de doenças nos municípios com a criação de programas preventivos que podem ser administrados observando-se as necessidades por meio dos dados epidemiológicos, que, por sua vez, são a base da elaboração do Plano Municipal da Saúde e do Plano Plurianual do Município. Tudo isso reunido faz com que os serviços sejam prestados com maior eficiência.

Os índices citados têm naturalmente relação entre si. A satisfação da população pode se dar, em grande parte, pela realização de um atendimento 
de qualidade, que resolva os casos de doenças e, consequentemente, reduza o índice de doenças no município.

A questão a seguir procurou identificar as maiores dificuldades enfrentadas na administração das secretarias municipais de saúde pesquisadas, de acordo com a opinião dos entrevistados. O objetivo dessa questão foi verificar se um sistema de custos poderia ajudar os gestores a resolver seus maiores problemas. A questão foi elaborada de forma que os entrevistados pudessem citar até três dificuldades de forma livre. Foi colocado ao lado dessa questão um quadro contendo alguns itens, onde os entrevistados puderam se basear para responder a questão.

Tabela 7

Problemas mencionados pelos entrevistados nas três colocações

\begin{tabular}{|lcc|}
\hline Respostas & Quantidade & $\%$ \\
\hline Questões relacionadas a problemas com funcionários da secretaria de saúde & 17 & 37,0 \\
Problemas relacionados com questões políticas & 9 & 19,6 \\
Questões relacionadas à falta de verbas & 8 & 17,4 \\
Questões relacionadas a problemas com a legislação pertinente & 5 & 10,9 \\
Questões relacionadas a problemas com credenciados & 4 & 8,7 \\
Falta de apoio à gestão da secretaria de saúde & 1 & 2,2 \\
Falta de tempo para administrar & 1 & 2,2 \\
Falta de conhecimento do SUS pelo usuário & 1 & 2,2 \\
\hline
\end{tabular}

Ao observar a tabela 7, nota-se que, das respostas obtidas, "questões relacionadas com problemas enfrentados com recursos humanos da secretaria de saúde" foram as mais mencionadas, (17 vezes, representando $37 \%$ das respostas), seguidas por "problemas relacionados com questões políticas" (nove vezes, representando $19,6 \%$ das respostas), insuficiências de verbas e problemas relacionados à legislação pertinente.

Entre os problemas relacionados aos recursos humanos, os entrevistados citaram: a falta de um plano de carreira para os funcionários; a falta de resolutividade por parte dos profissionais médicos; a falta de comprometimento por parte dos profissionais médicos; a falta de conhecimento sobre o SUS por parte da equipe; a falta de realização de planejamento por parte dos chefes de setores; a falta de conhecimento sobre administração pública por parte dos funcionários; a falta de qualificação dos funcionários; a falta de integração 
entre os setores da secretaria de saúde e a insuficiência de funcionários ocasionada por absenteísmo.

Os entrevistados salientaram que muitas das questões relacionadas a problemas enfrentados com recursos humanos são causadas por alguns profissionais médicos, pertencentes ao quadro da secretaria de saúde.

Problemas relacionados às questões políticas foram mencionados em segundo lugar. Alguns dos entrevistados comentaram que os políticos desconhecem o funcionamento da saúde pública e realizam interferências sem conhecimento de causa e sem dialogar com a secretaria de saúde anteriormente. Mencionaram também problemas enfrentados com "pedidos" realizados para eleitores, de forma a não seguir as regras normais para a concessão do benefício.

O problema da insuficiência de verbas foi o terceiro mais citado. Esse problema indica que um sistema de custos que permita uma maior economicidade na aplicação dos recursos pode ajudar bastante no processo.

A tabela 7 foi elaborada com base nos problemas mais importantes citados pelos entrevistados. Nesse caso, não se observou nenhuma alteração nos cinco problemas mais comentados, o que ratifica o resultado da tabela que mostra os problemas mais citados nas três colocações. Todos os 18 entrevistados informaram o problema maior.

\section{Conclusões}

Aqui são apresentadas as conclusões obtidas com a pesquisa, baseadas nos resultados apresentados.

Os objetivos foram alcançados. O perfil dos participantes da pesquisa foi caracterizado e as conclusões são as seguintes: todas as funções dos participantes da pesquisa são relacionadas com a administração das secretarias de saúde pesquisadas; $67 \%$ dos participantes têm menos de um ano de experiência na função, porém, $83 \%$ deles têm mais de cinco anos de experiência em saúde pública; $16,7 \%$ não possuem formação superior, do restante $38 \%$ apresentam formação na área da saúde, $27 \%$ formação na área de gestão e $17 \%$ em outras áreas; dos que possuem formação superior, 55,5\% têm especialização ou mestrado completos ou em curso; um declarou não ter acesso às informações da contabilidade do FMS, os demais tinham esse acesso; 71\% tinham acesso às informações do orçamento e/ou relatórios de despesas.

Foi verificada a existência de sistemas de custos nas secretarias municipais de saúde pesquisadas e a conclusão obtida foi que somente duas das secreta- 
rias municipais de saúde pesquisadas estão com o processo de implantação de sistemas de custos um pouco mais avançado, uma iniciou a implantação em 2005 e outra há mais tempo. Poucas das demais secretarias municipais de saúde pesquisadas possuem algumas informações de custos obtidas esporadicamente, porém sem a implantação de sistemas formais, e a maioria não possui informações de custos, utilizando somente as informações financeiras básicas, como orçamento, saldo em caixa e contas a pagar.

A percepção dos participantes da pesquisa sobre a importância de algumas informações de custos pôde ser levantada e a conclusão revela que, na opinião dos mesmos, tais informações são importantes e ajudam (ou ajudariam, se existissem) a melhorar a gestão dessas organizações.

Puderam ser identificadas quais informações de custos são utilizadas no processo de tomada de decisão e a conclusão a que se chegou é que poucas são as informações de custos utilizadas no processo de tomada de decisão pelos participantes da pesquisa, pois apenas três secretarias possuem o custo do atendimento médico e do atendimento de enfermagem. Duas possuem o custo por unidade de saúde e uma o custo de cada setor.

Em relação às informações de custos pesquisadas: as respostas indicam que os participantes da pesquisa acessam informações básicas a respeito de receitas e despesas; já informações de custos, são poucas as secretarias municipais de saúde que as possuem.

Somente a Secretaria Municipal de Saúde de Joinville e a de Balneário Camboriú possuem um sistema oficial de contabilidade de custos. Três secretarias apresentam algumas informações de custos fornecidas esporadicamente. Grande parte não possui as principais informações de custos.

A grande maioria considera as informações de custos importantes para a melhoria da gestão. As informações financeiras mais utilizadas no processo de tomada de decisão nas secretarias municipais de saúde pesquisadas são informações básicas sobre orçamento e despesas, saldo em caixa e contas a pagar.

A pesquisa pôde mostrar, de uma forma científica, o que antes era uma hipótese provável, ou seja, o processo de implantação da contabilidade de custos em 18 das 20 secretarias municipais de saúde do estado de Santa Catarina que mais receberam verbas do governo federal em 2004 está bastante lento, embora a Lei de Responsabilidade Fiscal (Lei no 101/2000), que exige tal implantação, esteja em vigor há mais de cinco anos. Entretanto, na opinião dos gestores dessas organizações públicas, as informações de custos são bastante importantes no processo de gestão. 


\section{Referências}

AFONSO, R. A. E. Modernização da gestão: uma introdução à contabilidade pública de custos. 2000. Disponível em: <www.bndes.gov.br/conhecimento/informeSF/ inf_18.pdf. $>$. Acesso em: 4 ago. 2004.

ALONSO, M. Custos no serviço público. Revista do Serviço Público, Brasília: Enap, ano 50, n. 1, 1999.

BEULKE, R.; BERTÓ, D. J. Gestão de custos e resultado na saúde. São Paulo: Saraiva, 1997.

BRASIL. Lei no 101, de 4 de maio de 2000. Estabelece normas de finanças públicas voltadas para a responsabilidade na gestão e dá outras providências.

. Lei $\mathrm{n}^{\circ}$ 8.080, de 19 de setembro de 1990. Regula, em todo o território nacional, as ações e serviços de saúde, executados isolada ou conjuntamente, em caráter permanente ou eventual, por pessoas naturais ou jurídicas de direito público ou privado.

. Lei no 8.142 , de 28 de dezembro de 1990. Dispõe sobre a participação da comunidade na gestão do Sistema Único de Saúde (SUS) e sobre as transferências intergovernamentais de recursos financeiros na área da saúde e dá outras providências.

. Constituição Federal. Brasília: Senado,1988.

CAMPOS, A C. Política de saúde. In: CONFERENCIA SOBRE POLÍTICAS DE DESENVOLVIMENTO ECONÔMICO E SOCIAL. Anais... Lisboa: IED, 1985.

CARPINTÉRO, J. N. C. Custos na área da saúde: considerações teóricas. In: CONGRESSO BRASILEIRO DE CUSTOS, 6. Anais... 1999.

CECÍLIO, L. C. de O. A modernização gerencial dos hospitais públicos: o difícil exercício da mudança. Revista de Administração Pública, Rio de Janeiro, v. 31, n. 3, p. 36-47, maio/jun. 1997.

CONASEMS (Conselho Nacional de Secretários Municipais de Saúde). Documento de teses e plano de ação. Disponível em: <www.conasems.org.br/>. Acesso em: out. 2005.

DATASUS (Departamento de Informática do SUS). Disponível em: <www.datasus. gov.br>. Acesso em: 2 ago. 2005.

FERNANDES, S. Entrevista realizada com o presidente do Conasems, Dr. Silvio Fernandes. Revista do Conasems, Brasília, ano I, n. 12, jun./jul. 2005. 
GONÇALVES, E. L. Estrutura organizacional do hospital moderno. Revista de Administração de Empresas, São Paulo, v. 38, n. 1, p. 80-90, jan./mar. 1998.

HORNGREN, C. T. et al. Contabilidade de custos. Rio de Janeiro: LTC, 2004.

MARTINS, E. Contabilidade de custos. São Paulo: Atlas, 2003.

MIOLA, C. Custos na administração pública. Porto Alegre: Tribunal de Contas do Estado do Rio Grande do Sul, 2001.

PEREIRA, J. R. T.; SILVA, A. C. A importância da implantação de sistema de custo para a gestão do setor público. In: CONGRESSO BRASILEIRO DE CUSTOS, 10., 2003. Anais... 2003.

QUINTO NETO, A.; MONTEGGIA, G. M. Práticas bem-sucedidas de interação dos médicos à gestão dos serviços de saúde. Porto Alegre: Promoarte, 1998.

RICHARDSON, R. J. Pesquisa social: métodos e técnicas. São Paulo: Atlas, 1999.

SANTA CATARINA. Secretaria de Estado da Saúde. Informações básicas para gestores do SUS. 2. ed. Florianópolis: SES, 2002.

SILVA, Alcione Carvalho da; PEREIRA, Jerônimo Rosário Tanan. A importância da implantação de sistema de custo para a gestão do setor público: O método activity based costing (ABC) como alternativa. In: CONGRESSO USP DE CONTABILIDADE E CONTROLADORIA, 2. Anais... 2003.

SILVA, I. L.; DRUMOND, R. B. A necessidade da utilização de sistema de custos e de indicadores de desempenho na administração pública. In: CONGRESSO USP DE CONTROLADORIA E CONTABILIDADE, 4. Anais... 2004.

SILVA, L. M da. Contribuição ao estudo para implantação de sistema de custos na administração pública. Brasília: Esaf, 1997. Disponível em: <www.tesouro.fazenda. gov.br/>. Acesso em: 3 ago. 2004.

WIEMER, A. P. M. ; RIBEIRO, Daniel Cerqueira. Custos no serviço público. In: CONGRESSO USP DE CONTROLADORIA E CONTABILIDADE, 4. Anais... São Paulo, 2004. (Demandas Sociais Emergentes e Pesquisa Contábil). 